\title{
Coastal Research Seen Through an Early Career Lens-A Perspective on Barriers to Interdisciplinarity in Norway
}

Anne Deininger ${ }^{1,2 * t}$, Angela H. Martin ${ }^{1 * t}$, Juan C. F. Pardo ${ }^{1,2}$, Paul R. Berg 1,2,3,4, Jyotirmoy Bhardwaj2,5, Diana Catarino', Albert Fernández-Chacón', Karen Martinez-Swatson ${ }^{3}$, Kotaro Ono6, Rebekah A. Oomen 1,4, Marte Sodeland', Tonje Knutsen Sørdalen ${ }^{1,3}$, Ann-Elin Wårøy Synnes ${ }^{1}$, Susanna Huneide Thorbjørnsen ${ }^{1,3}$ and Jonas Thormar ${ }^{3}$

\section{OPEN ACCESS}

Edited by:

Kelly Ortega-Cisneros,

University of Cape Town, South Africa

Reviewed by:

Jessica L. Blythe,

Brock University, Canada Michel Wahome,

University of Strathclyde, United Kingdom

*Correspondence: Anne Deininger

anne.deininger@niva.no Angela H. Martin

angelahelenmartin@gmail.com

${ }^{\dagger}$ These authors share first authorship

Specialty section:

This article was submitted to

Marine Conservation

and Sustainability,

a section of the journal

Frontiers in Marine Science

Received: 29 November 2020

Accepted: 15 March 2021

Published: 15 April 2021

Citation:

Deininger A, Martin AH, Pardo JCF, Berg PR, Bhardwaj J, Catarino D, Fernández-Chacón A, Martinez-Swatson K, Ono K,

Oomen RA, Sodeland $M$,

Sørdalen TK, Synnes A-EW, Thorbjørnsen SH and Thormar J

(2021) Coastal Research Seen Through an Early Career Lens - A

Perspective on Barriers

to Interdisciplinarity in Norway.

Front. Mar. Sci. 8:634999. doi: 10.3389/fmars.2021.634999
${ }^{1}$ Centre of Coastal Research, University of Agder, Kristiansand, Norway, ${ }^{2}$ Norwegian Institute for Water Research (NIVA), Oslo, Norway, ${ }^{3}$ Institute of Marine Research, Flødevigen, Norway, ${ }^{4}$ Centre for Ecological and Evolutionary Synthesis (CEES), University of Oslo, Oslo, Norway, ${ }^{5}$ Center of Intelligent Signal Processing and Wireless Networks (WISENET), University of Agder, Kristiansand, Norway, ${ }^{6}$ Institute of Marine Research, Bergen, Norway

The value of interdisciplinarity for solving complex coastal problems is widely recognized. Many early career researchers (ECRs) therefore actively seek this type of collaboration through choice or necessity, for professional development or project funding. However, establishing and conducting interdisciplinary research collaborations as an ECR has many challenges. Here, we identify these challenges through the lens of ECRs working in different disciplines on a common ecosystem, the Norwegian Skagerrak coast. The most densely populated coastline in Norway, the Skagerrak coast, is experiencing a multitude of anthropogenic stressors including fishing, aquaculture, eutrophication, climate change, land runoff, development, and invasive species. The Skagerrak coastline has also been the focus of environmental science research for decades, much of which aims to inform management of these stressors. The region provides a fantastic opportunity for interdisciplinary collaboration, both within and beyond the environmental sciences. This perspective article identifies the barriers ECRs in Norway face in establishing interdisciplinary and collaborative research to inform management of coastal ecosystems, along with their root causes. We believe our discussion will be of broad interest to all research institutions who employ or educate ECRs (in Norway and worldwide), and to those who develop funding mechanisms for ECRs and interdisciplinary research.

Keywords: early career researchers, interdisciplinarity, marine science and technology, Norway, ocean, Skagerrak

\section{INTRODUCTION}

In a time when global anthropogenic impacts on ecosystems call for urgent solutions, interdisciplinary collaboration can push the boundaries of marine research to enable innovative knowledge building and provide resource managers and policymakers with tools to secure a productive and healthy ocean (Ledford, 2015). As such, more than ever before, researchers are expected to think and work across disciplines to solve pressing challenges (Ledford, 2015; 
Rylance, 2015; Andrews et al., 2020). Across the globe, interdisciplinary institutes and think tanks push innovation by facilitating knowledge exchange (Ledford, 2015; Vienni Baptista et al., 2019; Mäkinen et al., 2020). The European Union framework program Horizon 2020 has heavily promoted interdisciplinary research, even so far as stating that it is the "key to future scientific breakthroughs," and awarded grants accordingly (Science Europe, 2012).

Early Career Researchers (ECRs) have an essential role within academic research, as driving forces that push science forward with research-focused workloads, fresh ideas, and enthusiasm (Friesenhahn and Beaudry, 2014; Andrews et al., 2020). Despite the documented benefits of interdisciplinarity, ECRs face many barriers to working successfully across disciplines (Table 1). The structure of academia is one such barrier, with fieldspecific funding calls, discipline-specific jargon, and short-term contracts, making interdisciplinary collaborations particularly challenging for ECRs (Brewer, 1999; Bromham et al., 2016; Andrews et al., 2020). This perspective article provides an overview of the barriers faced by ECRs within a recently established interdisciplinary research center in southern Norway, and their causes. To our knowledge, it is the first of its kind to focus on interdisciplinary coastal research in Norway and adds to the limited information on the topic in Scandinavia (Table 1 and see also Supplementary Material: Literature search).

With Norway being a maritime nation, the Norwegian government's long-term plan for research and higher education has a particular focus on research-based innovation and industry-oriented research, with the ocean being one of the priority areas (Norwegian Ministry of Education and Research, 2019). Investment in technology and research infrastructure is highlighted as crucial to promoting sustainable development and to increasing the value of industries in ocean and coastal areas. Norway's continued investment in this sector is reflected by the country having the world's highest proportion of marine scientists per capita (UNESCO-IOC, 2020). Norway could be used as an example by other countries of how to begin removing barriers for ECRs.

The aim of this article is to (1) identify barriers to interdisciplinary research faced by ECRs who work on a common ecosystem in Norway and (2) consider the root causes of these barriers. By sharing our perspective, we hope to draw attention to practices that need to be reviewed for more effective interdisciplinary research by ECRs in Norway and worldwide, leading to better informed management of coastal ecosystems during this time of global change. A background description of the Norwegian Centre for Coastal Research and the development of this manuscript can be found in the Supplementary Material (Supplementary Material: Background of This Study).

\section{COMMON BARRIERS TO ECR INTERDISCIPLINARITY}

To identify barriers to their research and their causes, the authors participated in individual and small-group work during winter and spring 2019/2020, then discussed these during a 3 days virtual workshop held in April 2020 (for details, see Supplementary Material: Background of this study). Three major themes emerged with regard to barriers, related to (1) short-term employment, (2) knowledge sharing via networks and partnerships, and (3) data-associated limitations (Figure 1). Within these themes, barriers were related to three main types of causes: (A) practical limitations hindering ECR research, (B) structural limitations inherent to the local research environment, and $(\mathrm{C})$ systemic limitations inherent to the current scientific, political, and societal situation in which research occurs (later referred to as "practical," "structural," and "systemic" causes, Figure 1).

This perspective is in agreement with previous work reporting that main barriers limiting ECRs' capacity for interdisciplinary research are not only of scientific origin but rather due to the working environment and conditions (Andrews et al., 2020; Brasier et al., 2020). A review of recent literature summarized in Table 1 suggests many diverse barriers to successful interdisciplinary collaborations for early career researchers. Since most of the barriers and their causes were raised by several researchers independently, we determined that these challenges occur across subdisciplines and will continue to hinder the progress of future ECRs unless they are addressed directly. As such, we outline below the identified barriers and causes. We acknowledge that our perspectives are biased toward our experiences in natural sciences and of being an ECR in Norway. Norway has comparatively favorable working conditions, specifically in relation to salary and gender equality at the ECR stage in our general field than many other countries. Furthermore, in Norway flatter structures are more common than in many other countries, which enables ECRs to engage with senior researchers and management staff more easily, as well as provide constructive criticism in regard to the work environment with less fear of repercussions. We discussed solutions, but given that we do not know the practicalities or secondary consequences of these, we have not made specific recommendations. Instead, we include our suggestions as a starting point for further discussion both briefly within the text and in more detail in Supplementary Material (Supplementary Material: Potential Solutions to Causes and Prevention of Barriers). In addition, solutions to the barriers identified in literature have been added to Table 1.

\section{Barrier 1: Temporary and Short-Term Contracts}

An overarching topic of our discussions related to temporary contracts and time limitations of short-term employment, which are not conducive to interdisciplinarity when considering the time investment needed to explore and establish collaborative research. There were several challenges associated with this barrier, such as pressure to publish; balancing time required to learn about the research environment, acquire skills, and conduct research; and job insecurity. The high competition for limited postdoc and permanent positions may not foster 
TABLE 1 | Summarized barriers to successful interdisciplinary research from an early career perspective and suggested solutions, from literature published since 2015.

\section{Barriers to ECR interdisciplinarity}

Poor research networks (e.g., due to relocation, institutional structures; Pannell et al., 2019; Fork et al., 2020)

Short duration of ECR positions, research time constraints (Bridle et al. 2013; Kelly et al., 2019; Pannell et al., 2019; Brasier et al., 2020; Fork et al., 2020)

Ineffective support: supervisory or institutional (Killion et al., 2018; Kelly et al., 2019; Andrews et al., 2020; Blythe and Cvitanovic, 2020; Fork et al., 2020)

\section{Proposed solutions}

- Bolster research networks through collaborative program structure and mentorship (Fork et al., 2020)

- Create ECR-focused spaces (e.g., regular ECR events, online communities, databases of ECR research, connect ECRs with complementary projects, funding for ECRs to attend encounters*; Pannell et al., 2019; Fork et al., 2020)

- Longer-term contracts, career development, and workshops on how to attract funding with salary support (Brasier et al., 2020)

- Access to established interdisciplinary networks (Brasier et al., 2020)

- Active support within integrative research communities (e.g., formalize mentorship, provide training, interdisciplinary courses, organize encounters ${ }^{\star}$, network building, provide seed funding, and follow-up activities; Lyall and Meagher, 2012; Bridle, 2018; Jaeger-Erben et al., 2018; Gibson et al., 2019; Pannell et al., 2019; Andrews et al., 2020)

- Establish good channels of communication (e.g., provide early feedback on nascent ideas, alert to imminent funding opportunities, dialog-led management; Gibson et al., 2019)

- Promote junior research group leaders, give the rank of junior professor (increases credibility with partners; Jaeger-Erben et al., 2018; Gibson et al., 2019)

Stress due to career uncertainty, including short-term employment contract (Bridle et al., 2013; Hein et al., 2018; Gibson et al., 2019; Andrews et al., 2020; Brasier et al., 2020; Fork et al., 2020) Traditional measure of success not appropriate for interdisciplinary work (manuscripts and citations, whereas interdisciplinary outputs are geared toward more real-world outcomes; Bridle et al., 2013; Hein et al., 2018; Jaeger-Erben et al., 2018; Martinez et al., 2018; Gibson et al., 2019; Pannell et al., 2019; Andrews et al., 2020; Blythe and Cvitanovic, 2020; Brasier et al., 2020)

Lack of funding/lack of access to funding (Hein et al., 2018; Pannell et al., 2019; Blythe and Cvitanovic, 2020; Bradley et al., 2020)

- Enable development of transferable skills useful across a wide range of potential careers (Brasier et al., 2020; Fork et al., 2020)

- Provide and normalize use of mental health support (Andrews et al., 2020)

- Promote sustainable working collaborations, counseling support, time, and funding for student support roles (Brasier et al., 2020)

- Acknowledge, support, and develop ways to measure alternative outputs (e.g., collaborations, cooperative learning, policy engagement, science communication outputs; Bridle et al., 2013; Pannell et al., 2019; Brasier et al., 2020)

- Integrate interdisciplinarity into research groups (e.g., graduate programs, training opportunities, develop interdisciplinary agendas; Haider et al., 2018; Martinez et al. 2018)

- Encourage recognition for interdisciplinarity from senior colleagues (Hein et al., 2018)

- Funding models to encourage interdisciplinary collaboration (e.g., to attend encounters ${ }^{\star}$, seed funding, travel advances; Bridle, 2018; Hein et al., 2018; Gibson et al., 2019; Pannell et al., 2019; Bradley et al., 2020)

- Active, practical support from institutions, funding bodies, and mentors (Pannell et al., 2019)

Limitations of hierarchical structures (Pannell et al., 2019; Brasier et al., 2020; Nash et al., 2020)

- Promote ECR into leadership positions (Gibson et al., 2019; Pannell et al., 2019)

- Facilitate supportive dialog between senior collaborators/researchers and ECRs (Gibson et al., 2019)

- Enforce codes of conduct to prevent harassment (Brasier et al., 2020)

Competition between ECRs (Pannell et al., 2019; Brasier et al., 2020)

- Facilitate knowledge and progress sharing between projects (Pannell et al., 2019)

- Create interdisciplinary work environments (Brasier et al., 2020)

Data issues (e.g., sharing, obtaining, accessing, managing; Drakou et al., 2017; Durden et al., 2017; Pannell et al., 2019)

- Create tools, infrastructure, and standards for data and data sharing (Drakou et al., 2017; Pannell et al., 2019; Wilson et al., 2021)

Difficulties associated with integrating divergent academic disciplines (e.g., different terminology, measurement scales; Palmer et al., 2016; Drakou et al., 2017; Hein et al., 2018; Hossain et al., 2018; Jaeger-Erben et al., 2018; McDonald et al., 2018; Gibson et al., 2019; Kelly et al., 2019; Pannell et al., 2019; Brasier et al., 2020; Wilson et al., 2021)

- Provide training and opportunities to practice (e.g., communication, team skills, disciplinary bias and reflexivity, relationship building; Hein et al., 2018; Hossain et al., 2018; Wilson et al., 2021)

- Facilitate interaction and development of relationships (e.g., encounters*; Palmer et al., 2016; Wilson et al., 2021)

- Invest in interdisciplinary infrastructure (e.g., journals, educational programs, connectivity between disciplines; Drakou et al., 2017; McDonald et al., 2018)

Managing work-life balance (Jaeger-Erben et al., 2018; Andrews et al. 2020; Brasier et al., 2020)

- Provide and normalize use of mental health support (Andrews et al., 2020)

- Provide career development opportunities and support (Haider et al., 2018)

- Outline expectations and limitations (Jaeger-Erben et al., 2018)

Complexity of initiating interdisciplinary work (e.g., steep learning curve, perform multiple roles; Bridle et al., 2013; Jaeger-Erben et al., 2018; Alexander et al., 2019; Gibson et al., 2019; Andrews et al., 2020)

- Integrate interdisciplinarity into research groups (e.g., graduate programs, training opportunities; Andrews et al., 2020)

- Provide guidance, training (e.g., in building networks, strategizing, time negotiation; Jaeger-Erben et al., 2018; Alexander et al., 2019)

- Provide and fund opportunities for networking across disciplines (e.g., encounters*; Bridle et al., 2013)

Individual skill requirements (Drakou et al., 2017; Durden et al., 2017; Cvitanovic et al., 2018; Elliott et al., 2018; Bohleber et al., 2020; Nash et al., 2020)
- Use professional development opportunities (e.g., mentor programs, skill development for interdisciplinarity, self-reflexivity, managing complexity and uncertainty, participation in interdisciplinary projects; Drakou et al., 2017; Cvitanovic et al., 2018; Elliott et al., 2018; Haider et al., 2018; Nash et al., 2020) 
TABLE 1 | Continued

Barriers to ECR interdisciplinarity Killion et al., 2018)

Lack of exposure to other disciplines (e.g., knowledge frameworks; Palmer et al., 2016; Hein et al., 2018; Killion et al., 2018; Gibson et al., 2019)

Difficulty of interdisciplinary publication (journal preference, reviewer expertise; Bridle et al., 2013; Drakou et al., 2017; Hein et al., 2018; Hossain et al., 2018; Gibson et al., 2019)

Geographical distance between collaborators (Rekers and Hansen, 2015)

Dominance of traditional (single-discipline) structure within academia (Lyall and Meagher, 2012; Hein et al., 2018)

Lack of interaction or tensions between collaborators (Palmer et al., 2016;

Blythe and Cvitanovic, 2020)

Different definitions of interdisciplinary (Gibson et al., 2019; Blythe and

Cvitanovic, 2020)

Early stage of career-still getting established in academia (Jaeger-Erben et al., 2018)

Language (Brasier et al., 2020)

Discrimination (Brasier et al., 2020)

\section{Proposed solutions}

- Maintain open communication to set and manage expectations (data, roles, outcomes,

skill gaps; Durden et al., 2017; Nash et al., 2020)

- Participate in ECR networks to build broad skillset (Bohleber et al., 2020)

- Provide networking and training opportunities (e.g., encounters*; Bridle, 2018; Killion et al., 2018)

- Improve integration of stakeholders in the research process and community (Killion et al., 2018)

- Provide training in communication, different knowledge frameworks, collaboration, and team skills (Palmer et al., 2016; Hein et al., 2018; Killion et al., 2018)

- Promote leaders to guide and facilitate teamwork (Palmer et al., 2016)

- Creation of interdisciplinary journals (Drakou et al., 2017)

- Spatial co-location of interdisciplinary centers (Rekers and Hansen, 2015)

- Expand networking opportunities (e.g., organize encounters ${ }^{\star}$ and provide training; Hein et al., 2018)

- Enable interpersonal and professional interactions, incorporate mechanisms that ensure engagement from multiple perspectives (Palmer et al., 2016; Blythe et al., 2017)

- Outline different knowledge framings and encourage plurality (Blythe et al., 2017)

- Outline expectations including scope and limitation (Jaeger-Erben et al., 2018)

- Training including: (1) soft skills (moderation, science communication), (2) best-practice

using example cases, (3) peer-peer learning (Jaeger-Erben et al., 2018)

- Provide experienced mentors (Jaeger-Erben et al., 2018)

- Language training and support, translate summaries, encourage non-English events (Brasier et al., 2020)

- Zero tolerance policies for discrimination (Brasier et al., 2020)

- Diverse research groups (Brasier et al., 2020)

- Encourage reporting of harassment and other abuses (Brasier et al., 2020)

*Encounters, referring to events designed to connect and encourage interdisciplinary networks and collaborative working. For details on how literature search was conducted, see Supplementary Material: Literature Search.

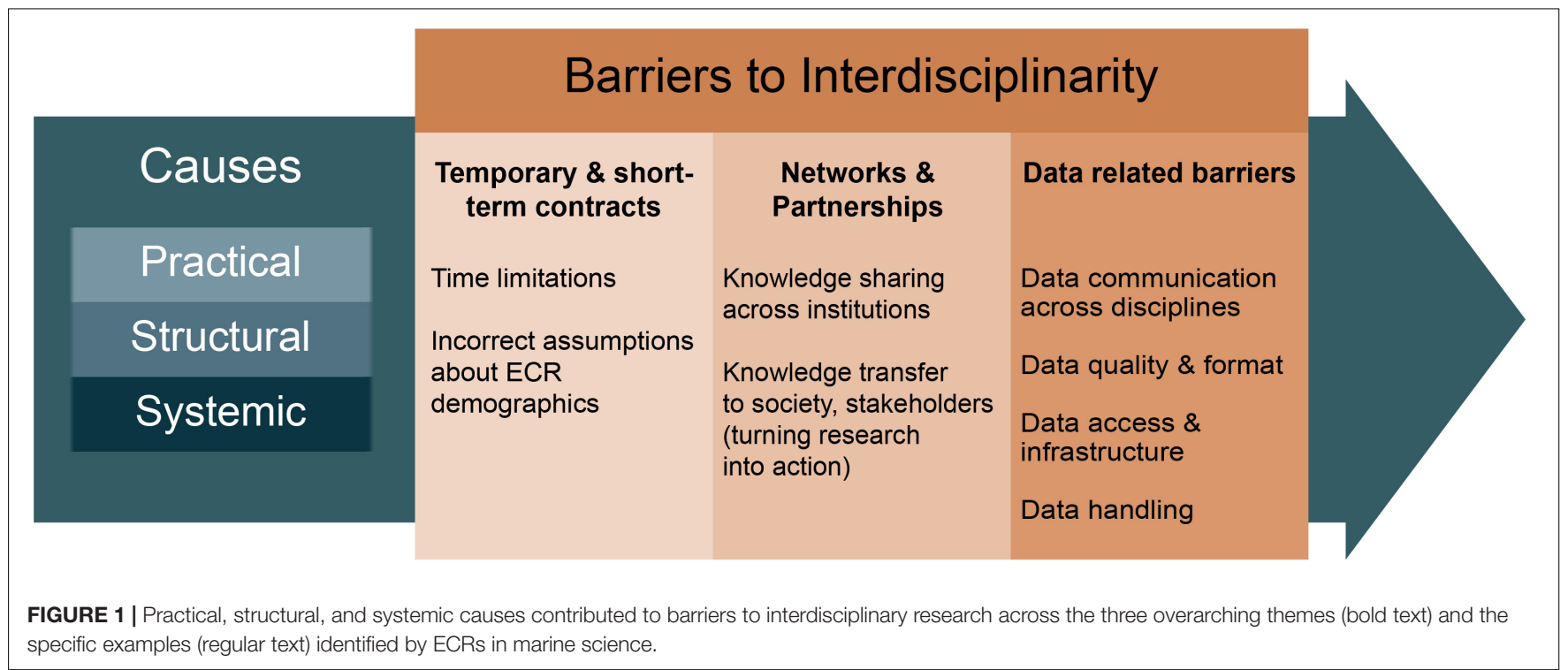

a collaborative working environment, as ECRs may feel they are in competition with their colleagues for limited resources. Time is a limiting factor for ECRs where, as a consequence, mental health and well-being suffer (Gewin, 2012; Woolston,
2018; Bosanquet et al., 2020; Table 1) with clinical symptoms such as depression and anxiety up to six times higher in graduate students compared to the general population (Evans et al., 2018). The problematic nature of short-term contracts for ECRs has 
become especially visible during the ongoing pandemic (Pardo et al., 2020). However, these problems were also identified by ECRs prior to COVID-19 and will not disappear post COVID19 if long-term solutions are not created on all levels (Figure 1 and Supplementary Table 1). Furthermore, there is a growing body of literature related to career uncertainty in general and the associated economic and personal costs (Garwood, 2014; Bozzon et al., 2017; Chesters et al., 2019; Table 1). Underlying practical, structural, and systemic causes were identified, as detailed below.

\section{Practical Causes}

Practical reasons that short-term contracts are a barrier to ECRs establishing successful interdisciplinary projects include lengthy processes, such as finding potential collaborators and developing project plans that suit all partners; designing and trialing new experimental methods, which often have unpredictable results and timeframes; and seasonal limitations on field sampling or laboratory experiments.

\section{Structural Causes}

Time limitations due to fixed-term contracts may also become a barrier for several practical reasons. Many tasks ECRs have to complete during their short-term employment may be mandatory or prescribed by their local research environment (i.e., following of internal routines and procedures). As specific examples, such time-demanding tasks may be (1) mandatory legislative approval for data collection or animal welfare approval for practical work, mandatory safety, lab, and method training. Although recognized as highly important, these tasks may be overly time consuming if proper guidance is not provided immediately. (2) ECRs depend on cyclical and highly competitive funding opportunities to cover field and lab expenses-funding opportunities which may have months between initial application, decision, and receipt of grant money. (3) Furthermore, interdisciplinarity requires working outside of an ECR zone-of-knowledge, whereby completing tasks and learning new methods may require additional time (Andrews et al., 2020). Lastly, (4) while learning native language is not a requirement for international staff on temporary contracts in most institutions in Norway, much of the communication between colleagues is conducted in the native speech. Such informal discussions are generally a great source for learning about colleagues' work and opportunities to collaborate. Language courses are often only provided to permanent staff and, where available to temporary employees, are often at extra costs (time and money). Free language classes may sometimes be available at affiliated universities; however, those may not be frequent enough to provide the practice required to adequately engage in conversation until the end of the temporary contracts and are often not at the appropriate level to enable work-related conversation (Mentzoni et al., 2016).

\section{Systemic Causes}

ECRs are typically expected to move during their academic career in order to expand their research and network horizon, i.e., take temporary positions (Bridle et al., 2013; Brasier et al.,
2020; Fork et al., 2020). This funding and employment system appears to be driven by several assumptions, in particular the ECRs' ability to relocate, i.e., the traditional view of ECRs as young, able, single, or with a stay-at-home spouse who is willing and able to relocate, and not as parents or carers for vulnerable relatives, or unable to relocate for other reasons (Jaeger-Erben et al., 2018; Andrews et al., 2020; Brasier et al., 2020). However, this assumption is exclusionary to the majority of our ECR authors who do not fit that demographic. There may also be an assumption that forced relocation to a new research environment, e.g., as a postdoctoral researcher in another country, is more valuable than longterm employment within one location. Yet, shorter research visits and exchanges with partner sites, instead of contractual relocation, can be an efficient option for knowledge transfer in both directions and on various levels (on a national, institutional, and individual level). In addition, while new knowledge and new studies could be conducted at the partner site, ongoing research and networks at the already established "home institute" could be maintained and continued, making investment in interdisciplinary partnerships more likely.

\section{Barrier 2: Networks and Partnerships (Knowledge Sharing Across Institutions)}

Sharing of methods, data, and knowledge among disciplines is essential to pushing scientific frontiers forward. Barriers to interdisciplinarity identified by ECRs included access to appropriate networks, establishing successful collaborations, and overcoming communication barriers between disciplines (Supplementary Table 2 and Table 1). ECRs may largely depend on input from collaborators, supervisors, and senior academics, which may not fully acknowledge the needs of the ECRs or provide the required guidance. The problem is asymmetric, as for ECRs future employment may depend on successful interdisciplinary research experience while the project may not be pivotal for the careers of the senior researchers involved. Reluctance in sharing methods, data, and knowledge between individuals, research groups, disciplines, or even research generations was found to be a barrier to successful collaborations for ECRs.

\section{Practical Causes}

We identified several practical causes, such as the lack of holistic perspectives in the planning of data collection and experimentation, the difficulties in communication and open data sharing between disciplines and new partner institutions, the traditional divisions among sciences and the different types of knowledge produced, and lack of resources or technical limitations.

\section{Structural Causes}

Engagement with stakeholders, practitioners, and local authorities, as well as the broader society is a prerequisite for turning research into action and to overcoming real-time coastal challenges in a long-lasting way. However, a lack of such established networks within research centers may prevent ECRs 
from connecting with relevant contacts and implementing their research. Interdisciplinary research institutes may be able to help ECRs overcome those structural barriers by actively promoting encounters between ECRs and already established networks (Bridle et al., 2013; MacLeod, 2018).

\section{Systemic Causes}

Time and funding may be too limited to contact, exchange, and develop novel methods in collaboration with partners during an ECR contract. Although the general attitude toward sharing has largely improved over the past decade, sharing methods across disciplines and with new contacts can still be challenging. Often, collaborators may not be willing to share, contribute, or exchange expertise with new members, as ECRs will be less "known" compared to more senior researchers within collaborator networks and so may be less trusted with data. As a result, ECRs may not have access to new methods before they are published. Publication of novel, interdisciplinary methods may be more time demanding than traditional methods as reviewers or editors may be more skeptical or perceive themselves as less qualified to review the manuscript.

\section{Barrier 3: Data-Related Barriers}

Reliable data is an integral part of research and remains so for interdisciplinary collaboration. Data acquisition, cleaning, normalization, and integration across interdisciplinary areas are an inherent part of ECR work. Technical advancements can provide significant assistance by simplifying the data acquisition process. The barriers we identify affect ECRs' research in terms of quality, quantity, and efficiency (Table 1). Resolving data-related issues will not only improve the ECRs efficiency but also help the interdisciplinary research centers by ensuring their position at the forefront of research and help equip the next generation of interdisciplinary scientists to handle the rapidly increasing amount of data available (Supplementary Table 3). We identified four broad barriers related to data:

(A) Data communication. Communication barriers hinder the smooth sharing and coordination of data between different disciplines. Challenges arise in dissemination and publication of research activities that integrate the expertise of many domains, such as marine biology, chemistry, ecotoxicology, computer science, including reporting of results, and technical language.

(B) Data quality and format. All the ECR participants experienced challenges in integrating data for interdisciplinary research, despite having access to the datasets they needed.

(C) Data access and infrastructure-ECRs may not be in possession of their data, instead relying on institutes, senior researchers, and collaborative companies to access their databases and platforms. In some cases, ECRs may rely on the willingness of different project stakeholders for data access and later feel indebted to them (e.g., eternal inclusion on project ideas, papers). Furthermore, in our experience, database management is not the primary priority of project stakeholders, and often only few people know the nature of data (e.g., metadata). To meet the international standards of high impact work, addressing these issues is inherently crucial to ECRs' work.
(D) Data handling. Traditionally, data acquisition was a manual process, especially within biology. "Big data" has become a mainstay of research due to advancement in technology, particularly sensors and remote observations, and exponential growth in internet capabilities and various open and online data platforms for visualization and analytics. The use of such datasets and platforms requires big data skills as well as knowledge of data security. ECRs therefore need to update and maintain these skill sets but are seldom provided with training opportunities to do so.

\section{Practical Causes}

With regard to data communication barriers (A), data collection and storage are often not designed for collaborators in different subfields to understand and use, and ECRs often lack sufficient knowledge about other topics and tools to share data in ways meaningful outside their own disciplines. Data quality and format (B) became a barrier for ECRs working with inherited data where, despite substantial efforts in the past to standardize and clean datasets by different researchers, data inconsistencies could not be eliminated. Furthermore, legacy data from senior researchers or online databases inherit errors that new recipients are unaware of. Regarding data access and infrastructure $(\mathrm{C})$, the lack of transparent and replicable routines for data management and storage often prevents the use of existing data. Practical causes of barriers related to data handling (D) include a lack of common framework in open and online data platforms that enable interdisciplinary usage of data. Finally, in some overlap with the temporary and short-term contract barriers, time constraints for ECRs are an overarching practical cause of the interdisciplinary data-related barriers above. For example, reliable and relevant data acquisition often relies on manual sampling, a time-consuming, often seasonally limited process, and data cleaning, management, and handling take time to master when considerations must be made for use by other disciplines.

\section{Structural Causes}

(A) The discipline-specific organization of universities inhibits interdisciplinary discussions and development of a common language between disciplines. (B) Past data cleansing efforts are not being circulated and shared in professional circles (Ma et al., 2018), and the absence of institutional frameworks for data collection and format leads to inconsistent entries or data exclusion. (C) There is a lack of integrative open and online data platforms, and decisions are yet to be made regarding who should be responsible for dealing with such challenges: individual researchers, ECRs, research centers, external companies handling external servers, universities, or governments (Durden et al., 2017). Therefore, ECRs need the specific support from project stakeholders and universities to establish networks with big data and data security specialists. (D) There is a lack of recognition of the importance of developing skill sets for handling big data across disciplines and lack of institutional capacity available to train ECRs. Large-scale data science initiatives can help to maximize the use of interdisciplinary data for both individual researchers and the research community as a whole by providing 
concepts, analytical tools, and training materials (e.g., the Big Data to Knowledge initiative of the National Institutes of Health for biomedical big data; Margolis et al., 2014). Such initiatives will likely disproportionately improve ECRs' datarelated challenges.

\section{Systemic Causes}

(A) Traditional division of academic disciplines continues to hinder smooth communication of data and interdisciplinary results. For example, professional societies and publication outlets are often organized by a specialist topic and may not promote interdisciplinary content or have trained interdisciplinary editors and reviewers, who can translate the languages of different disciplines and uphold the quality of interdisciplinary research (McLeish and Strang, 2016). (B) We noted a lack of research funding and human resources invested in continuous monitoring programs and long-term data collection. (C) The conflicts of interests between the scientific community, universities, institutes, researchers, and project stakeholders hinder the data acquisition process of ECRs, for example through access to potential data sources. (D) The lack of a common data framework established by international regulatory bodies.

\section{CONCLUDING THOUGHTS}

Interdisciplinary research centers are well-positioned to both lead work to solve complex ocean challenges and to share knowledge through collaborations between public, private, academic, and community groups. We encourage researchers tackling global environmental challenges to increase collaboration across fields but also across career stages. In particular, we encourage more senior researchers and institutes to include and support ECRs in their longterm funding planning, their research networks, and their active research to help overcome the above-described barriers (Supplementary Tables 1-3).

Finally, as ECRs in Norway, we recognize our privilege in earning a salary through our research that enables us to live comfortably without the necessity of a second job, and with a reasonable level of job security for the duration of our contracts. These conditions contribute to a better work environment than is the case for many ECRs globally. It is likely that ECRs at other research centers, within and outside of Norway, will experience additional barriers and may differ in terms of priorities (for limitations of this study, see Supplementary Material: Limitations of this study). In sum, we consider that the barriers highlighted in this article are likely to be close to baseline that is applicable to ECRs around the world (Table 1). We suggest that shorter research visits and exchanges with partner sites could be explored to replace contractual relocation during temporary and shortterm contracts (Barrier 1). This will continue to encourage knowledge transfer as well as enable ECRs to establish successful interdisciplinary projects at a "home institute." Creation of interdisciplinary strategies and infrastructure for collaboration by institutions could enable knowledge sharing both within and between institutions, improve access to methods within the research community, and facilitate networking opportunities for ECRs (Barrier 2). Improved data management standards and associated training at all career stages will reduce data-related barriers to interdisciplinary research for ECRs and all levels of a research organization (Barrier 3). We hope our perspective will help to improve the work and working conditions for ECRs in interdisciplinary settings and ultimately improve the search for solutions to complex ocean challenges.

\section{DATA AVAILABILITY STATEMENT}

The original contributions presented in the study are included in the article/Supplementary Material, further inquiries can be directed to the corresponding author/s.

\section{AUTHOR CONTRIBUTIONS}

$\mathrm{AD}$ and $\mathrm{AM}$ conceived, designed, and organized the workshops and the resulting perspective together and wrote a first draft of this manuscript with main help from JP, as well as inputs from all co-authors via the workshop events and on an initial outline. All authors critically revised the text.

\section{FUNDING}

Funding for the workshops was granted by the Centre for Coastal Research. RAO was supported by a James S. McDonnell Foundation Postdoctoral Research Fellowship.

\section{ACKNOWLEDGMENTS}

We thank the Centre for Coastal Research (CCR) for funding the workshops that allowed the writing of this work and encouraged us to reflect on our ECR experience. We would like to thank the CCR Board and other senior colleagues for fruitful discussions and feedback, and Kim Halvorsen for valuable input during the initiation phase. Special thanks to Halvor Knutsen, Hans Weinberger, and the two reviewers for their valuable input on earlier versions of the manuscript.

\section{SUPPLEMENTARY MATERIAL}

The Supplementary Material for this article can be found online at: https://www.frontiersin.org/articles/10.3389/fmars.2021. 634999/full\#supplementary-material 


\section{REFERENCES}

Alexander, K. A., Hobday, A. J., Cvitanovic, C., Ogier, E., Nash, K. L., Cottrell, R. S., et al. (2019). Progress in integrating natural and social science in marine ecosystem-based management research. Mar. Freshw. Res. 70, 71-83. doi: 10. 1071/MF17248

Andrews, E. J., Harper, S., Cashion, T., Palacios-Abrantes, J., Blythe, J., Daly, J., et al. (2020). Supporting early career researchers: insights from interdisciplinary marine scientists. ICES J. Mar. Sci. 77, 476-485. doi: 10.1093/icesjms/fsz247

Blythe, J., and Cvitanovic, C. (2020). Five organizational features that enable successful interdisciplinary marine research. Front. Mar. Sci. 7:981. doi: 10. 3389/fmars.2020.539111

Blythe, J., Nash, K., Yates, J., and Cumming, G. (2017). Feedbacks as a bridging concept for advancing transdisciplinary sustainability research. Curr. Opin. Environ. Sustain. 26, 114-119. doi: 10.1016/j.cosust.2017.05.004

Bohleber, P., Casado, M., Ashworth, K., Baker, C. A., Belcher, A., Caccavo, J. A., et al. (2020). Successful practice in early career networks: insights from the polar sciences. Adv. Geosci. 53, 1-14. doi: 10.5194/adgeo-53-1-2020

Bosanquet, A., Mantai, L., and Fredericks, V. (2020). Deferred time in the neoliberal university: experiences of doctoral candidates and early career academics. Teach. High. Educ. 25, 736-749. doi: 10.1080/13562517.2020. 1759528

Bozzon, R., Murgia, A., Poggio, B., and Rapetti, E. (2017). Work-life interferences in the early stages of academic careers: the case of precarious researchers in Italy. Eur. Educ. Res. J. 16, 332-351. doi: 10.1177/1474904116669364

Bradley, A., Höfer, J., Savaglia, V., and Eayrs, C. (2020). Survey on early career travel support shows geographic, career stage, and indigenous status inequality in access to polar science events. Adv. Geosci. 53, 73-85. doi: 10.5194/adgeo-5373-2020

Brasier, M. J., McCormack, S., Bax, N., Caccavo, J. A., Cavan, E., Ericson, J. A., et al. (2020). Overcoming the obstacles faced by early career researchers in marine science: lessons from the marine ecosystem assessment for the Southern Ocean. Front. Mar. Sci. 7:692. doi: 10.3389/fmars.2020.00692

Brewer, G. D. (1999). The challenges of interdisciplinarity. Policy Sci. 32, 327-337.

Bridle, H. (2018). Following up on interdisciplinary encounters: benefits for early career researchers. Eur. Rev. 26(S2), S6-S20. doi: 10.1017/S1062798718000236

Bridle, H., Vrieling, A., Cardillo, M., Araya, Y., and Hinojosa, L. (2013). Preparing for an interdisciplinary future: a perspective from early-career researchers. Futures 53, 22-32. doi: 10.1016/j.futures.2013.09.003

Bromham, L., Dinnage, R., and Hua, X. (2016). Interdisciplinary research has consistently lower funding success. Nature 534, 684-687. doi: 10.1038/ nature 18315

Chesters, J., Smith, J., Cuervo, H., Laughland-Booy, J., Wyn, J., Skrbiš, Z., et al. (2019). Young adulthood in uncertain times: the association between sense of personal control and employment, education, personal relationships and health. J. Sociol. 55, 389-408. doi: 10.1177/1440783318800767

Cvitanovic, C., Löf, M. F., Norström, A. V., and Reed, M. S. (2018). Building university-based boundary organisations that facilitate impacts on environmental policy and practice. PloS One 13:e0203752. doi: 10.1371/journal. pone. 0203752

Drakou, E. G., Kermagoret, C., Comte, A., Trapman, B., and Rice, J. C. (2017). Shaping the future of marine socio-ecological systems research: when earlycareer researchers meet the seniors. ICES J. Mar. Sci. 74, 1957-1964. doi: 10. 1093/icesjms/fsx009

Durden, J. M., Luo, J. Y., Alexander, H., Flanagan, A. M., and Grossmann, L. (2017). Integrating "big data" into aquatic ecology: challenges and opportunities. Limnol. Oceanogr. Bull. 26, 101-108. doi: 10.1002/lob.10213

Elliott, L., Ryan, M., and Wyborn, C. (2018). Global patterns in conservation capacity development. Biol. Conserv. 221, 261-269. doi: 10.1016/j.biocon.2018. 03.018

Evans, T. M., Bira, L., Gastelum, J. B., Weiss, L. T., and Vanderford, N. L. (2018). Evidence for a mental health crisis in graduate education. Nat. Biotechnol. $36: 282$.

Fork, M., Anderson, E., Castellanos, A., Fischhoff, I., Matsler, A., Nieman, C., et al. (2020). Creating community: how we collectively built an adaptable postdoctoral program to develop skills and overcome isolation. Authorea doi: 10.22541/au.160519333.36036478/v1
Friesenhahn, I., and Beaudry, C. (2014). The Global State of Young Scientists. Project Report and Recommendations. Berlin: Global Young Academy.

Garwood, R. (2014). Uprooting researchers can drive them out of science. Nat. News 510:313. doi: 10.1038/510313a

Gewin, V. (2012). Mental health: under a cloud. Nature 490, 299-301. doi: 10.1038/ nj7419-299a

Gibson, C., Stutchbury, T., Ikutegbe, V., and Michielin, N. (2019). Challenge-led interdisciplinary research in practice: program design, early career research, and a dialogic approach to building unlikely collaborations. Res. Eval. 28, 51-62. doi: 10.1093/reseval/rvy039

Haider, L. J., Hentati-Sundberg, J., Giusti, M., Goodness, J., Hamann, M., Masterson, V. A., et al. (2018). The undisciplinary journey: early-career perspectives in sustainability science. Sustain. Sci. 13, 191-204. doi: 10.1007/ s11625-017-0445-1

Hein, C. J., Ten Hoeve, J. E., Gopalakrishnan, S., Livneh, B., Adams, H. D., Marino, E. K., et al. (2018). Overcoming early career barriers to interdisciplinary climate change research. Wiley Interdiscip. Rev. Clim. Change 9:e530. doi: 10.1002/wcc. 530

Hossain, M. S., Pogue, S. J., Trenchard, L., Van Oudenhoven, A. P. E., Washbourne, C.-L., Muiruri, E. W., et al. (2018). Identifying future research directions for biodiversity, ecosystem services and sustainability: perspectives from earlycareer researchers. Int. J. Sustain. Dev. World Ecol. 25, 249-261. doi: 10.1080/ 13504509.2017.1361480

Jaeger-Erben, M., Kramm, J., Sonnberger, M., Völker, C., Albert, C., Graf, A., et al. (2018). Building capacities for transdisciplinary research: challenges and recommendations for early-career researchers. GAIA-Ecol. Perspect. Sci. Soc. 27, 379-386. doi: 10.14512/gaia.27.4.10

Kelly, R., Mackay, M., Nash, K. L., Cvitanovic, C., Allison, E. H., Armitage, D., et al. (2019). Ten tips for developing interdisciplinary socio-ecological researchers. Socio Ecol. Pract. Res. 1, 149-161.

Killion, A. K., Sterle, K., Bondank, E. N., Drabik, J. R., Bera, A., Alian, S., et al. (2018). Preparing the next generation of sustainability scientists. Ecol. Soc. 23:39. doi: $10.2307 / 26796895$

Ledford, H. (2015). How to solve the world's biggest problems. Nat. News 525:308. Lyall, C., and Meagher, L. R. (2012). A masterclass in interdisciplinarity: research into practice in training the next generation of interdisciplinary researchers. Futures 44, 608-617. doi: 10.1016/j.futures.2012.03.011

Ma, X., Beaulieu, S. E., Fu, L., Fox, P., Di Stefano, M., and West, P. (2018). "Documenting provenance for reproducible marine ecosystem assessment in open science," in Information Retrieval and Management: Concepts, Methodologies, Tools, and Applications, (Hershey: IGI Global), 1051-1077.

MacLeod, M. (2018). What makes interdisciplinarity difficult? Some consequences of domain specificity in interdisciplinary practice. Synthese 195, 697-720. doi: 10.1007/s11229-016-1236-4

Mäkinen, E. I., Evans, E. D., and McFarland, D. A. (2020). The patterning of collaborative behavior and knowledge culminations in interdisciplinary research centers. Minerva 58, 71-95. doi: 10.1007/s11024-019-09381-6

Margolis, R., Derr, L., Dunn, M., Huerta, M., Larkin, J., Sheehan, J., et al. (2014). The national institutes of health's Big Data to Knowledge (BD2K) initiative: capitalizing on biomedical big data. J. Am. Med. Inf. Assoc. 21, 957-958. doi: 10.1136/amiajnl-2014-002974

Martinez, G., Armaroli, C., Costas, S., Harley, M. D., and Paolisso, M. (2018). Experiences and results from interdisciplinary collaboration: utilizing qualitative information to formulate disaster risk reduction measures for coastal regions. Coast. Eng. 134, 62-72. doi: 10.1016/j.coastaleng.2017.09.010

McDonald, K. S., Hobday, A. J., Fulton, E. A., and Thompson, P. A. (2018). Interdisciplinary knowledge exchange across scales in a globally changing marine environment. Glob. Chang. Biol. 24, 3039-3054.

McLeish, T., and Strang, V. (2016). Evaluating interdisciplinary research: the elephant in the peer-reviewers' room. Palgrave Commun. 2:16055. doi: 10.1057/ palcomms. 2016.55

Mentzoni, T. M., Egeland, C., Drange, I., Askvik, T., Støren, L. A., Røsdal, T., et al. (2016). Being a Foreigner is no Advantage"-Career Paths and Barriers for Immigrants in Norwegian Academia. Report number 2016:12. Oslo: Work Research Institute(AFI).

Nash, K. L., Alexander, K., Melbourne-Thomas, J., Novioaglio, C., Sbrocchi, C., Villanueva, C., et al. (2020). Developing achievable alternate futures for key 
challenges during the UN decade of ocean science for sustainable development. Rev. Fish Biol. Fish. 3, 1-18. doi: 10.1007/s11160-020-09629-5

Norwegian Ministry of Education and Research (2019). Long-Term Plan For Research And Higher Education 2019-2028. Meld. St. 4. (2018-2019) Report to the Storting (white paper). Oslo: Norwegian Ministry of Education and Research, 48.

Palmer, M. A., Kramer, J. G., Boyd, J., and Hawthorne, D. (2016). Practices for facilitating interdisciplinary synthetic research: The National SocioEnvironmental Synthesis Center (SESYNC). Curr. Opin. Environ. Sustain. 19, 111-122. doi: 10.1016/j.cosust.2016.01.002

Pannell, J. L., Dencer-Brown, A. M., Greening, S. S., Hume, E. A., Jarvis, R. M., Mathieu, C., et al. (2019). An early-career perspective on encouraging collaborative and interdisciplinary research in ecology. Ecosphere 10:e02899. doi: $10.1002 /$ ecs 2.2899

Pardo, J. C., Ramon, D., Stefanelli-Silva, G., Elegbede, I., Lima, L. S., and Principe, S. C. (2020). Advancing through the pandemic from the perspective of marine graduate researchers: challenges. Solut. Oppor. Front. Mar. Sci. 7:528. doi: 10. 3389/fmars.2020.00528

Rekers, J. V., and Hansen, T. (2015). Interdisciplinary research and geography: overcoming barriers through proximity. Sci. Public Policy 42, 242-254. doi: $10.1093 /$ scipol/scu048

Rylance, R. (2015). Grant giving: global funders to focus on interdisciplinarity. Nature 525, 313-315.

Science Europe (2012). Science Europe Position Statement Horizon 2020: Excellence Counts. Bruxelles: Science Europe.
UNESCO-IOC (2020). Global Ocean Science Report 2020: The Current Status of Ocean Science Around the World. Paris: UNESCO-IOC.

Vienni Baptista, B., Vasen, F., and Villa Soto, J. C. (2019). Interdisciplinary centers in Latin American Universities: the challenges of institutionalization. High. Educ. Policy 32, 461-483. doi: 10.1057/s41307-0180092-x

Wilson, M. N., Laufer, A. E., Howard, E. M., and Wong-Ala, J. A. T. K. (2021). Lessons from the trenches: students' perspectives of their own marine transdisciplinary education. Front. Mar. Sci. 7:592368. doi: 10.3389/fmars.2020. 592368

Woolston, C. (2018). Feeling overwhelmed by academia? You are not alone. Nature 557, 129-129. doi: 10.1038/d41586-018-04998-1

Conflict of Interest: The authors declare that the research was conducted in the absence of any commercial or financial relationships that could be construed as a potential conflict of interest.

Copyright (c) 2021 Deininger, Martin, Pardo, Berg, Bhardwaj, Catarino, FernándezChacón, Martinez-Swatson, Ono, Oomen, Sodeland, Sørdalen, Synnes, Thorbjørnsen and Thormar. This is an open-access article distributed under the terms of the Creative Commons Attribution License (CC BY). The use, distribution or reproduction in other forums is permitted, provided the original author(s) and the copyright owner(s) are credited and that the original publication in this journal is cited, in accordance with accepted academic practice. No use, distribution or reproduction is permitted which does not comply with these terms. 